Prithi Pal Singh MD, Ivan Dimich MD, Ian Sampson MD, Norman Sonnenklar MD

\title{
A comparison of esmolol and labetalol for the treatment of perioperative hyper- tension in geriatric ambulatory surgical patients
}

This is an open randomized study comparing the efficacy and safety of iv esmolol and labetalol in the treatment of perioperative hypertension in ambulatory surgery. Twenty-two elderly patients undergoing cataract surgery under local anaesthesia were studied. The main inclusion criteria were development of systolic blood pressure $>200 \mathrm{mmHg}$ or diastolic $>100$ $\mathrm{mmHg}$. Esmolol was given as a bolus $500 \mu \mathrm{g} \cdot \mathrm{kg}^{-1}$ iv followed by a maintenance infusion $\left(150-300 \mu \mathrm{g} \cdot \mathrm{kg}^{-1} \cdot \mathrm{min}^{-1}\right)$. Labetalol was given as a bolus of $5 \mathrm{mg}$ iv followed by $5 \mathrm{mg}$ increments as needed up to a maximum of $1 \mathrm{mg} \cdot \mathrm{kg}^{-1}$. Esmolol and labetalol both produced reductions in systolic and diastolic blood pressure $(P<0.05)$ within ten minutes of administration which lasted for at least two hours. Reduction of blood pressure by esmolol was accompanied by a decrease in $H R(P<0.05)$. Two patients developed extreme bradycardia (HR $<50$ beats $\cdot \mathrm{min}^{-1}$ ) and esmolol had to be discontinued. Labetalol, in contrast, induced only a moderate decrease in HR. None of the

\section{Key words}

ANAESTHESIA: geriatric;

BLOOD PRESSURE: hypertension;

SURGERY: ambulatory;

SYMPATHETIC NERVOUS SYSTEM: pharmacology, esmolol, labetalol.

From the Department of Anesthesiology, Mount Sinai School of Medicine, New York, NY and City Hospital Center at Elmhurst, Elmhurst, NY.

Presented in part at the Annual Meeting of ASA, Las Vegas, October, 1990.

Address correspondence to: Dr. Dimich at the Department of Anesthesiology, Mount Sinai Hospital, One Gustave L. Levy Place, Box 1010, New York, NY 10029, U.S.A.

Accepted for publication 21st March, 1992. patients treated with labetalol experienced any prolonged side effects such as orthostatic hypotension. In conclusion, esmolol may produce considerable bradycardia in elderly patients when hypertension is not accompanied by tachycardia. Labetalol was easier to administer in the ambulatory setting and one-tenth the cost of esmolol.

Il s'agit d'une étude randomisée comparant l'efficacité et la sécurité du traitement avec esmolol et labétalol iv de l'hypertension per-opératoire lors de la chirurgie ambulatoire. Nous avons étudié 22 patients âgés subissant une chirurgie pour cataracte sous anesthésie locale. Les critères d'inclusion principaux étaient l'apparition d'une tension artérielle systolique plus grande que $200 \mathrm{mmHg}$ ou diastolique plus grande que $100 \mathrm{mmHg}$. Le traitement à l'esmolol comprenait un bolus de $500 \mu \mathrm{g} \cdot \mathrm{kg}^{-1}$ iv suivi d'une perfusion de 150 à $300 \mu \mathrm{g} \cdot \mathrm{kg}^{-1} \cdot \mathrm{min}^{-1}$. Le traitement au labétalol comprenait un bolus de $5 \mathrm{mg}$ iv suivi d'une dose de $5 \mathrm{mg}$ selon les besoins jusqu'à un maximum de $1 \mathrm{mg} \cdot \mathrm{kg}^{-1}$. L'esmolol et le labétalol ont diminué les tensions artérielle systoliques et diastoliques $(P<0,05)$ en dedans de dix minutes après leur administration, effet qui a persisté pour au moins deux heures. La diminution de la tension artérielle par l'esmolol était accompagnée par une diminution de la fréquence cardiaque $(P<0,05)$. Deux patients ont présenté une bradycardie sévère (fréquence cardiaque $<50$ battements $\cdot \mathrm{min}^{-1}$ ) et l'esmolol a dâ être cessé. Le labétalol ne causait qu'une diminution modérée de la fréquence cardiaque. Aucun des patients traités avec labétalol n'a montré d'effets secondaires prolongés importants tel que l'hypotension orthostatique. En conclusion, l'esmolol peut causer une bradycardie importante chez les patients agés lorsque l'hypertension n'est pas accompagnée de tachycardie. Le labétalol est plus facile à administrer dans le contexte ambulatoire, et ce à un coût dix fois moins important que l'esmolol. 
The treatment of perioperative hypertension in ambulatory surgery remains a therapeutic dilemma for anaesthetists. Many vasodilator drugs require invasive monitoring and can elicit reflex tachycardia. This tachycardia can be deleterious in the patient with ischaemic heart disease. On the other hand, labetalol which is an alpha and beta blocker, does not induce tachycardia, but may produce prolonged hypotension. ${ }^{1}$

Esmolol, an ultra short-acting cardioselective beta, blocker has been shown to be effective in the management of intraoperative tachycardia and hypertension. ${ }^{2-5}$ Its elimination half-life is approximately nine minutes, ${ }^{2}$ and this unique pharmacological property makes esmolol particularly attractive in the treatment of acute hypertension during ambulatory surgery. Esmolol also provides a margin of safety in those patients, such as the elderly, with multiple cardiovascular problems who are least able to tolerate the adrenergic response to perioperative stimuli.

Intraocular surgery, especially cataract extraction, is one of the most commonly performed procedures in ambulatory patients. The majority undergoing this procedure are elderly and have multiple medical problems, one of the most common of which is hypertension. The purpose of this study was to determine the efficacy and safety of esmolol compared with labetalol for the management of perioperative hypertension in ambulatory surgical patients. We are unaware of any previous studies that have used esmolol for this purpose.

\section{Methods}

This study was approved by the Institutional Review Board and all patients gave written consent prior to entry.

\section{Patient selection and description}

Twenty-two elderly patients who were scheduled for elective cataract surgery under local anaesthesia and who developed perioperative hypertension were included. Exclusion criteria were atrioventricular conduction block greater than first degree, sick sinus syndrome, uncompensated heart failure, a history of myocardial infarction within the past six months, and chronic obstructive pulmonary disease or asthma that would preclude beta blockade.

Patients who received monoamine oxidase inhibitors or catecholamine-depleting agents, such as reserpine, within the past six weeks were also excluded.

All patients underwent a prestudy evaluation which consisted of a medical history, physical examination, and 12-lead ECG. Blood pressure and heart rate were recorded in the preoperative room and used as control values. From the initial group of 132 scheduled for surgery, 22 patients developed perioperative hypertension. There
TABLE I Preoperative patient characteristics

\begin{tabular}{lll}
\hline Parameters & Esmolol $(n=I I)$ & Labetalol $(n=I I)$ \\
\hline Age $(\mathrm{yr})$ & $78 \pm 9$ & $75 \pm 8$ \\
Sex ratio $(\mathrm{M} / \mathrm{F})$ & $5 / 7$ & $4 / 6$ \\
Body weight $(\mathrm{kg})$ & $66 \pm 12$ & $68 \pm 9$ \\
$\begin{array}{l}\text { Chronic hypertension } \\
\text { Preoperative beta-blocker } \\
\quad \text { therapy }\end{array}$ & 6 & 7 \\
\hline
\end{tabular}

were 13 women and 9 men. Their ages ranged from 70-91 yr with an average age of $76 \mathrm{yr}$. Thirteen patients were chronically hypertensive. Seven patients were currently receiving beta adrenergic receptor blocking drugs, and four were receiving a calcium channel blocker. Patients were instructed by their private physicians to take their medication up to and including the morning before surgery (Table I).

As a group, these patients had extensive cardiovascular medical problems including arteriosclerotic heart disease, peripheral vascular disease, stroke, diabetes mellitus and chronic renal failure.

\section{Protocol}

Perioperative hypertension was defined as a systolic blood pressure greater than $200 \mathrm{mmHg}$ and/or diastolic blood pressure greater than $100 \mathrm{mmHg}$ demonstrated on two successive blood pressure readings taken five minutes apart. The perioperative period was defined as the time from entering the operating room until leaving the recovery room. All patients were monitored with continuous electrocardiogram (ECG), a noninvasive automatic blood pressure cuff (Dinamap, Tampa, FL), a digital pulse oximeter (Nellcor, Hayward, CA) and a precordial stethoscope. Only patients having surgery under local anaesthesia with retrobulbar block were studied. Before initiation of antihypertensive therapy, attempts were made to eliminate primary causes of hypertension. For anxiety, midazolam, $1 \mathrm{mg} i \mathrm{v}$, was given to all patients before administration of antihypertensive therapy. For bladder distention patients were encouraged to urinate before or during surgery. A small dose of thiamylal, 50 $\mathrm{mg}$, was administered just before the retrobulbar block. Retrobulbar block was performed using a mixture of bupivacaine $0.75 \%$ and lidocaine $2 \%$.

Those who developed hypertension were randomized to receive either intravenous esmolol (Group E), or labetalol (Group L). The initial dose of esmolol was a bolus of $0.5 \mathrm{mg} \cdot \mathrm{kg}^{-1}$ followed by maintenance infusion ranging from 150 to $300 \mu \mathrm{g} \cdot \mathrm{kg}^{-3} \cdot \mathrm{min}^{-1}$. Labetalol was administered as a bolus of $5 \mathrm{mg}$ followed by $5 \mathrm{mg}$ increments as needed every five minutes up to a maximum dose of $1 \mathrm{mg} \cdot \mathrm{kg}^{-1}$. Blood pressure and heart rate were recorded every two minutes during administration of antihypertensive drugs before surgery and during 
TABLE II Haemodynamic values before and after intravenous infusion of esmolol and labetalol

\begin{tabular}{|c|c|c|c|c|c|c|c|c|}
\hline & \multirow[b]{2}{*}{ Group } & \multicolumn{5}{|c|}{ Time after start of drug administration (min) } & \multicolumn{2}{|c|}{ Discharge from $R R$} \\
\hline & & Baseline & 10 & 30 & 60 & 120 & Sitting & Standing \\
\hline \multirow{2}{*}{$\begin{array}{l}\text { Systolic BP } \\
(\mathrm{mmHg})\end{array}$} & $\mathrm{E}$ & $217 \pm 12.3$ & $175 \pm 7.0^{*}$ & $171 \pm 3.4^{*}$ & $173 \pm 6.2^{*}$ & $175 \pm 3.6^{*}$ & $178 \pm 2.4^{*}$ & $177 \pm 4.8^{*}$ \\
\hline & $\mathrm{L}$ & $218 \pm 11.6$ & $174 \pm 12.5^{*}$ & $175 \pm 7.4^{*}$ & $169 \pm 4.7^{*}$ & $170 \pm 8.3^{*}$ & $175 \pm 6.2^{*}$ & $173 \pm 5.0^{*}$ \\
\hline \multirow{2}{*}{$\begin{array}{c}\text { Diastolic BP } \\
(\mathrm{mmHg})\end{array}$} & $\mathrm{E}$ & $102 \pm 8.1$ & $84 \pm 4.4^{*}$ & $79 \pm 3.2^{*}$ & $77 \pm 2.8^{*}$ & $82 \pm 3.4^{*}$ & $85 \pm 4.4^{*}$ & $84 \pm 2.0^{*}$ \\
\hline & $\mathrm{L}$ & $103 \pm 14.4$ & $87 \pm 10.0^{*}$ & $82 \pm 7.4^{*}$ & $79 \pm 6.3^{*}$ & $76 \pm 5.8^{*}$ & $79 \pm 3.0^{*}$ & $77 \pm 5.6^{*}$ \\
\hline \multirow{2}{*}{$\begin{array}{l}\text { Heart rate } \\
\text { beats } \cdot \mathrm{min}^{-1}\end{array}$} & $E$ & $81 \pm 9.3$ & $61 \pm 8.5 \dagger$ & $62 \pm 9.1 \dagger$ & $65 \pm 7.8^{*}$ & $72 \pm 6.8$ & $71 \pm 5.2$ & $71 \pm 3.2$ \\
\hline & L & $78 \pm 8.5$ & $71 \pm 6.3$ & $72 \pm 4.2$ & $69 \pm 5.8$ & $70 \pm 8.2$ & $68 \pm 4.3$ & $69 \pm 6.0$ \\
\hline
\end{tabular}

Mean values $\pm \mathrm{SD}$.

${ }^{*} P<0.05$ within group (vs baseline).

$\dagger P<0.05$ between groups.

Group E received esmolol.

Group $\mathrm{L}$ received labetalol.

performance of the retrobulbar block. During surgery as well as in the recovery room, blood pressures and heart rates were recorded every $15 \mathrm{~min}$. A therapeutic response was defined as a $20 \%$ reduction in SBP and or a DBP reduction to less than $100 \mathrm{mmHg}$. Esmolol infusion was discontinued at the end of the operation.

In the Recovery Room, blood pressure and heart rate were recorded in the supine or sitting position. Upon discharge vital signs were obtained in the sitting and standing positions to document lack of orthostatic hypotension.

\section{Data analysis}

Data were analyzed using multivariate analysis of variance (MANOVA). Data were expressed as mean \pm SD. A statistically significant difference was assumed when $P$ was less than 0.05 .

\section{Results}

There was no significant difference between the groups with respect to age and weight. The patients' demographic data are listed in Table I. In all patients, control blood pressures were less than $180 \mathrm{mmHg}$ (mean value $175 \mathrm{mmHg}$ ) systolic and $100 \mathrm{mmHg}$ diastolic (mean value $92 \mathrm{mmHg}$ ). There were no differences between the groups in baseline systolic and diastolic blood pressures or heart rates. Esmolol reduced systolic arterial pressure from $217 \pm 12.3 \mathrm{mmHg}$ (range 208 to $240 \mathrm{mmHg}$ ) to $175 \pm 4.0 \mathrm{mmHg}$. Labetalol reduced systolic arterial pressure from $218 \pm 11.6 \mathrm{mmHg}$ (range 201 to $232 \mathrm{mmHg}$ ) to $174 \pm 12.5 \mathrm{mmHg}$ (Table II) ( $P$ $<0.05$ ). Although both groups showed a reduction in blood pressure from baseline, there was no precipitous decrease in blood pressure in either group during the study period. Ten of 11 patients in each group met the pressure reduction criteria and therefore were classified as responders.

In comparison with control (preoperative) HR, there was no rise in HR during hypertension in either group. In the esmolol group, control $\mathrm{HR}$ was $74 \pm 4$ beats $\cdot \mathrm{min}^{-1}$ and increased to $81 \pm 9$ beats $\cdot \mathrm{min}^{-1}$. In the labetalol group, HR increased from control $72 \pm 6$ to 78 \pm 8 beats $\cdot \mathrm{min}^{-1}$.

Administration of esmolol slowed heart rate from 81 \pm 9 to $61 \pm 8$ beats $\cdot \mathrm{min}^{-1}(P<0.05)$. Two of these patients developed bradycardia ( $\mathrm{HR}<50$ beats $\cdot \mathrm{min}^{-1}$ ) and esmolol was temporarily discontinued. One of these patients had been treated chronically for hypertension with propranolol. She had received the last dose of propranolol $12 \mathrm{hr}$ before surgery. In contrast to esmolol, administration of labetalol was associated with a modest insignificant decline in HR from $78 \pm 8$ to $71 \pm 6$ beats $\cdot \min ^{-1}$ (Table II). The average duration of the surgery was 45-60 min. Esmolol infusion was continued during surgery and discontinued at the end of the procedure. The average duration of administration of esmolol was 60-70 min.

The mean time to onset of the response in the esmolol group was $7.4 \pm 3.9 \mathrm{~min}$ (range 5 to $10 \mathrm{~min}$ ) while the mean time in the labetalol group was $10 \pm 2 \mathrm{~min}$ (range 5 to $15 \mathrm{~min}$ ). The average dose of esmolol needed to achieve the desired blood pressures ranged from $150-200 \mu \mathrm{g} \cdot \mathrm{kg}^{-1} \cdot \mathrm{min}^{-1}$, and in the labetalol group, dose ranged from $10-15 \mathrm{mg}$.

During their stay in the recovery room, all patients showed a sustained therapeutic response. None of the patients experienced any untoward prolonged side effects from labetalol, such as postural hypotension or dizziness.

\section{Discussion}

The unique group of patients we studied were considerably older than those reported in other studies in which esmolol has been used. Major predisposing factors included a history of preexisting hypertension (12 patients), poorly controlled hypertension or early discontinuation of antihypertensive medication before 
surgery. Five of our patients who failed to take their antihypertensive medication on the morning of surgery developed perioperative hypertension. Other factors including anxiety, pain, or the routine installation of vasoconstricting ophthalmic solutions (epinephrine, neosynephrine) may also have contributed to the development of hypertension. The exact aetiology of perioperative hypertension in unclear. Moss et al. ${ }^{6}$ reported, in a study on the stress response in patients undergoing cataract surgery, that hypertension was associated with elevated plasma concentrations of epinephrine and norepinephrine indicating sympathetic stimulation. This adrenergic response, in general, creates a hyperdynamic circulatory state manifested by increases in HR, BP and myocardial contractility. In our study, we did not find any increase in heart rate during hypertensive episodes. This is consistent with the findings of other investigators who have found minimal increases in heart rate in elderly patients during sympathetic stimulation. Vestal $e t a l^{8}$ investigated in vivo beta adrenoreceptor function in humans and found that the heart rate response to isoproterenol decreased progressively with aging. In addition, the elderly have been reported to be less sensitive to the beta adrenergic blocking effect of propranolol. ${ }^{7}$ These findings imply an age-related decreasing sensitivity of cardiac beta $a_{1}$ adrenergic receptors to both agonist and antagonist.

Additional reasons for a blunting of the reflex tachycardia in some of our patients included the use of beta-blockers for preoperative treatment of hypertension and the presence of autonomic neuropathy in diabetics.

Esmolol, in the moderate dose range of 150-200 $\mu \mathrm{g} \cdot \mathrm{kg}^{-1} \cdot \mathrm{min}^{-1}$, produced a slowing of the heart rate in our patients. From these findings, there is no indication that the elderly are less sensitive to the beta adrenergic blocking effect of esmolol. Scott et al. ${ }^{9}$ have shown that with aging, alpha-, receptor responsiveness is not altered. This is of particular importance when labetalol is used as an antihypertensive agent in elderly patients. Labetalol blocks both beta and alpha- ${ }_{1}$ adrenoreceptors. ${ }^{10}$ The alpha $_{1}$ adrenoreceptor blocking action of labetalol decreases peripheral vascular resistance and blood pressure with little alteration in heart rate and cardiac output. ${ }^{11,12}$ In the current study, labetalol produced prompt and smooth reduction of blood pressure without significant alteration in heart rate. This effect was maintained for at least two hours. Prolonged alpha, blockade produced by labetalol may cause orthostatic hypotension, and for this reason $i v$ labetalol has not been recommended in the past for patients who will soon be ambulatory. ${ }^{11,12}$ In the current study, the use of a small initial $i v$ dose of labetalol appeared to avoid any precipitous reduction in blood pressure during surgery or orthostatic hypotension prior to discharge. Most of our patients were discharged from the recovery room three hours following administration of labetalol. At that time there were no prolonged side effects present from labetalol. As the plasma half life of labetalol is $5.5 \mathrm{hr}$, we would anticipate fewer such complications as time goes on.

In conclusion, both iv esmolol and labetalol when administered in fixed incremental doses, are equally effective in controlling perioperative hypertension. However, esmolol may produce a bradycardia in the elderly requiring discontinuation of the drug. We found that labetalol was easier to administer and one-tenth of the cost of esmolol. Based on our findings, esmolol did not offer any advantage over labetalol in the treatment of perioperative hypertension in elderly ambulatory surgical patients undergoing cataract extraction under local anaesthesia.

\section{References}

1 McCarthy E, Bloomfield S. Labetalol: a review of its pharmacology, pharmacokinetics, clinical uses and adverse effects. Pharmacotherapy 1983; 3: 93-119.

2 Menkhaus P, Reves J, Kissin I, et al. Cardiovascular effects of esmolol on anesthetized humans. Anesth Analg 1985; 64: 327-34.

3 Murphy $V$, Hwang T, Sandage V, Laddu A. Esmolol and the adrenergic response to peripheral stimuli. J Clin Pharmacol 1986; 26: A27-A35.

4 Reynolds $R$. Gorczynski $R$, Quon $C$. Pharmacology and pharmacokinetics of esmolol. J Clin Pharmacol 1986; 26: A3-A14.

5 Katavia B, DuBois $M$, Gadde $P$, et al. Evaluation of esmolol for treatment of postoperative hypertension. Anesth Analg 1990; 70: S192.

6 Moss J, Donion J, McGold R. Stress response to local anesthesia for cataract surgery. Anesthesiology 1987;67: $3 \mathrm{~A}$.

7 Lakatta $E$. Alterations in the cardiovascular system that occur in advanced age. Fed Proc 1979; 38: 163-7.

8 Vestal R, Wood A, Shaud D. Reduced B-adrenoreceptor sensitivity in the elderly. Clin Pharmacol Ther 1979; 26: 181-5.

9 Scott $P$. The effect of age on the responses of human isolated arteries to noradrenaline. $\mathrm{Br} \mathrm{J} \mathrm{Clin} \mathrm{Pharmacol}$ 1982; 13: 237-9.

10 Cressman $M$, Vidth $D$, Gifford $R$. Intravenous labetalol in the management of severe hypertension and hypertensive emergencies. Am Heart J 1987; 101: 980-5.

11 Willson $D$, Wallin $R$, Vlachakis $N$, Freis $E$. Intravenous labetalol in the treatment of severe hypertension and hypertensive emergencies. Am J Med 1983; 72: 95-101.

12 Leslie J, Kaluyjian R, Sirgu M, Plachetka J, Watkins D. Intravenous labetalol for treatment of postoperative hypertension. Anesthesiology 1987; 67: 413-6. 